\title{
A Study on the Cross-cultural Communication Strategies of Yue Opera
}

Lou Lingling (Corresponding author)

School of English Language, Zhejiang Yuexiu University, China

Email: rolinlou@foxmail.com

Received: 02/12/2020

Accepted: 22/02/2021

Published: 01/03/2021

Volume: 2 Issue: 2

How to cite this paper: Lingling, L. (2021). A Study on the Cross-cultural Communication Strategies of Yue Opera. Journal of Critical Studies in Language and Literature, 2(2), 53-59

DOI: https://doi.org/10.46809/jcs1l.v2i2.61

Copyright ( 2020 by author(s) and Global Talent Academy Ltd. This work is licensed under the Creative Commons Attribution International License (CC BY 4.0).

http://creativecommons.org/licenses/by/4.0/

\section{(c) (i)}

\begin{abstract}
Yue Opera, the second-largest opera in China, is also known as "the most widely spread local opera genre in China". It is called "Chinese Opera" abroad. The overseas dissemination of Yue Opera has extremely far-reaching significance for displaying traditional Chinese culture, telling Chinese stories well, and building cultural confidence. Based on combing the status quo of overseas communication of Yue Opera in different stages, the paper analyzes the currently existing problems, and then, under the guidance of Lasswell's Model of Communication, discusses cross-cultural communication strategies of Yue Opera from five aspects, namely "who", "says what", "in which channel”, "to whom" and "with what effect".
\end{abstract}

Keywords: Cross-cultural Communication Strategies, Yue Opera, Lasswell's Model of Communication

\section{Introduction}

\subsection{Background of the Study}

As a unique type of drama originating in Zhejiang, Yue Opera has strong local characteristics. It is mainly derived from the Shengzhou dialect and folk music. It draws on the essence of Shaoxing Opera, Beijing Opera, Kunqu Opera, and other operas as well as dramas, movies, and other art forms. It has achieved a unique artistic style and is known as "a shining pearl in Jiangnan".

Originating in Shengzhou, Shaoxing, Zhejiang Province in 1906, Yue opera features actresses in male roles as well as femininity in terms of singing, performing, and staging. Despite its rural origin, it has found a second home in Shanghai, China's most affluent city, where it managed to out-compete both Beijing Opera and the native Shanghai Opera. The most famous plays of Yue Opera include A Dream of Red Mansions, The Romance of Western Chamber and Liang Shanbo and Zhu Yingtai, which is a kind of Chinese version of Romeo and Juliet.

In recent years, with the rapid development of China's economy and society, cultural and art undertakings have made great progress. As an important carrier of traditional Chinese culture, traditional Chinese drama has been playing a significant role in the international arena. However, due to the highly stylized performance of Chinese traditional drama, language and cultural differences, and other factors, the acceptance of Chinese drama by foreign audiences is still relatively limited. To better spread Chinese culture and tell Chinese stories, this paper intends to explore the cross-cultural communication strategies of Yue Opera under the guidance of Lasswell's Model of Communication.

1.2. Significance of the Study

First, the study of cross-cultural communication of Yue Opera consists with the need of its inheritance and development. On the one hand, the overseas dissemination of Yue Opera brings business opportunities for the development of Yue Opera 
and makes Chinese people see its broader development prospect. As cultural undertakings are developing towards marketization, exploring overseas markets is of great significance to the prosperity and development of Yue Opera. On the other hand, studying the cross-cultural communication of Yue Opera from the perspective of communication science can not only broaden the academic vision of Yue Opera research but also provide empirical experience for cross-cultural communication research, which also has strong reference and practical significance for the inheritance and development of traditional Chinese opera.

Second, the study of cross-cultural communication of Yue Opera is in line with the requirements of the "Chinese Culture Going Global" strategy. With the development of economic globalization, international cultural exchanges are very frequent. But in terms of culture, China is still in a weak position in the world. The biased reports of foreign media have deepened foreigners' misunderstanding of the Chinese people. Chinese opera culture, as the representative of the traditional culture of the nation, carries the Chinese people's values of loving peace and yearning for mutual respect. The dissemination of Chinese traditional opera can sow the seeds of Chinese traditional culture in the hearts of foreign people, attract more overseas people's attention to Chinese traditional culture, eliminate misunderstanding, building a stronger relationship, and obtain a favorable international public opinion environment for China's development. With the proposal of the "Chinese Culture Going Global" strategy, the rapid development of new media, the globalization of cultural dissemination, and the internationalization of cultural classics, how to creatively spread the traditional opera art and tell the "Chinese story" in opera on the world stage is a key problem to be solved. Besides, promoting the cross-cultural communication of Yue Opera plays an important role in improving the national cultural soft power and promoting the development of China's economy. Therefore, in the context of cultural globalization, the cross-cultural communication of Yue Opera is a very important cultural exchange project. It is an important mission for every practitioner and cultural communicator of Yue Opera to better spread this traditional art overseas.

\section{Lasswell's Model of Communication}

Harold Lasswell (1948), an American political scientist and one of the four founders of communication studies, clearly put forward the communication process and its five basic elements, namely: who, says what, in which channel, to whom, and with what effect. This mode is concise and clear, and it is regarded as a classic theory in communication. Many scholars have revised, supplemented, and developed it, but most of them retained its essential characteristics. This model also established the five basic components of communication research: control analysis, content analysis, media analysis, audience analysis, and effects analysis.

Each of the five elements has its characteristics. "Who" is the communicator, responsible for the collection, processing, and transmission of information in the process of communication. The communicator can be a single person, it can also be a collective or a specialized organization. "Says what" refers to the content of the message, which is a combination of information composed of a set of meaningful symbols. These symbols include not only verbal symbols but also non-verbal symbols. "In which channel" is the medium or material carrier through which information must be transmitted. It can be interpersonal media such as letters and telephones, or mass media such as newspapers, radio, and television. "To whom" is the recipient or audience. The audience is the general term for all recipients such as readers, listeners, audiences, etc. It is the ultimate object and destination of the communication. "With what effect" is the reaction caused by the information on the cognitive, emotional, and behavioral levels after it reaches the audience. It is an important yardstick to test the success of communication activities.

Harold Lasswell first proposed the Five W's of Communication in 1932, however, at that time, it is far from being a mature theory. Later, after 16 years of repeated revisions and supplements by Lasswell, the version we see now came into being. The theory for the first time clearly expressed communication activities as a process of five links and elements, which laid the scope and basic content of communication research and provided a specific starting point for people to understand the structure and characteristics of the communication process.

Lasswell's contribution lies in that he correctly pointed out the main direction of communication research through the Five W's of Communication, which made the main force of communication research focus on investigating and studying the basic elements of the communication process in nearly half a century, thus laying a solid foundation for the rapid development of the whole communication science.

\section{Status Quo of Overseas Communication of Yue Opera}

The external communication of opera includes the overseas dissemination of drama texts, stage performances, video products, etc. The acceptance of opera by heterogeneous culture includes the evaluation, translation, adaptation, performance, and research of opera by audiences of heterogeneous cultures $(\mathrm{Xu}, 2013)$.

The inheritance and evolution of Yue Opera have a history of one hundred years. Although it enjoys a high reputation in China, its overseas promotion is not as good as Beijing Opera, Kunqu Opera, and other traditional operas. In CNKI, by taking "Yue Opera" and "overseas communication" as keywords and eliminating repetitive and irrelevant literature, a total of 6 effective journal papers were obtained. After reviewing the literature, it is found that the number of journal papers published on this topic is relatively small. The papers are all published after 2017, and the number of published papers is 
increasing year by year, which also shows that there has been an increased emphasis on "overseas communication of Yue Opera" in recent years. Nevertheless, generations of performing artists of Yue Opera have been adhering to the combination of tradition and innovation, and actively promoting the overseas dissemination of Yue Opera. Liang Shanbo and Zhu Yingtai, the first opera film after the founding of new China, opened the door for Yue Opera to go global. Later, A Dream of Red Mansions, The Romance of Western Chamber, etc were performed overseas one after another. After the policy of "letting a hundred flowers blossom and pushing out the new" was launched in the last century, the cross-cultural communication of Yue Opera has gone through several stages: overseas communication at the government level, overseas communication promoted by government and non-governmental organizations, and diversified overseas communication.

3.1. Overseas Communication at the Government Level

In the 1950s and 1960s, while inheriting the tradition, Yue Opera made great efforts to innovate, trying to combine realistic performance techniques such as modern drama and film with traditional opera, to expand the spread scope of traditional Yue Opera. At this stage, the overseas communication of Yue Opera was mainly based on national communication, and the main channels of communication were overseas visiting performances and overseas exhibitions of Yue Opera films.

Liang Shanbo and Zhu Yingtai, which was produced in 1953, is the first large-scale opera film after the founding of new China. It was screened during the Geneva Conference and received rave reviews, which reversed the prevailing theory of "the Communist Party does not want culture" in the western world at that time (Wang, 1993). Xu Yulan, Wang Wenjuan, and other well-known performing artists of Yue Opera have visited and performed in Korea, Germany, the Soviet Union, Vietnam, and other countries. Representative repertoires include a batch of classic plays showcasing traditional Chinese culture and virtues such as Liang Shanbo and Zhu Yingtai and The Romance of West Chamber. In 1955, the Chinese Yue Opera Troupe visited the German Democratic Republic and the Soviet Union to perform. The literary and art circles in Democratic Germany and the Soviet Union highly praised The Romance of West Chamber and Liang Shanbo and Zhu Yingtai as wonderful poems showing affinity to the people. The Soviet drama critic Hubov praised Chinese Yue Opera for being able to discard many outdated, stale things and preserve the long-standing and excellent tradition with the spirit of true democracy. Besides, he regarded The Romance of West Chamber as an excellent artwork that has true musicality and aesthetic feeling and is fascinating. The drama critic Kabalevsky wrote a review article in Pravda, praising Yue opera for being good at combining the most abundant and long tradition of classical opera with the realism of modern drama, and cherishing and developing its own national culture. A message from TASS said the audience praised Liang Shanbo and Zhu Yingtai as "Romeo and Juliet of China". A German writer published an article in the Evening News saying, "although people have language difficulties, they can understand everything. It can make people feel incomparable joy and infinite grief in the process of watching the performance. I've seen the perfect art. It's so simple and real, just like the mirror reflecting the human soul." (Cai \& Chen, 2011)

All of these communications expand the overseas audience's artistic vision to understand the richness of Chinese drama, and at the same time, make an excellent cultural interpretation for the international image of new China.

3.2. Overseas Communication Promoted by Government and Non-governmental Organizations

In addition to the performances organized by the government, many art exchanges and commercial performances among non-governmental organizations also appeared in the overseas communication of Yue Opera in the 1980s and 1990s. During this period, Shanghai Yue Opera Troupe, Hangzhou Yue Opera Troupe, Zhejiang Xiaobaihua Yue Opera Troupe, Ningbo Xiaobaihua Yue Opera Troupe, etc. have all gone abroad for visiting performances, art festival exchanges, and commercial performances.

In 1983, young actors from Shanghai Yue Opera Theater performed A Dream of Red Mansions in Japan. In 1986, Shanghai Yue Opera Theater went to Paris, France to participate in the Paris Autumn Art Festival. In May 1989, a group of artists from Shanghai Yue Opera Theater visited the United States for performances, and they were warmly welcomed and highly praised by people from all over the world. In 1990, Lv Ruiying, Fan Ruijuan, Zhang Guifeng, etc., accompanied the Chinese National Art Delegation to perform in the Federal Republic of Germany, France, the Netherlands, Belgium, Luxembourg and other countries with programs such as My Wife is Princess. In 1994, Lv Ruiying was awarded the "Asia's Most Outstanding Artist Award" by the American-Chinese Art Association in New York.

In the late 1990s, with the transformation of society and culture, the types of art such as movies and television were prospering, and the stage art of opera was declining. However, Yue Opera artists have actively explored and innovated in the theme and artistic style of Yue Opera, combining the local development with overseas expansion. In this way, Yue Opera has succeeded to expand its popularity overseas.

\subsection{Diversified Overseas Communication}

With the proposal of the "Chinese Culture Going Global" strategy, the country attaches great importance to the overseas dissemination of traditional operas. As one of the representatives of traditional operas, Yue Opera often goes abroad for exchanges and performances to convey the spirit of Chinese traditional culture. Various non-governmental organizations and individuals are constantly exploring new ways of overseas communication of Yue Opera and expanding commercial performance channels.

On August 17, 2001, Shaoxing Xiaobaihua Yue Opera Troupe went to Thailand to participate in the Asian Folk Theater Festival. Its performance of the excellent traditional opera Liang Shanbo and Zhu Yingtai in the Thai Cultural Center was highly praised by Thai audiences and overseas friends. There was endless applause in the performance. After watching the 
first show, many audiences scrambled for tickets for the second one. Qin Yusen, Cultural Counselor of the Chinese Embassy in Thailand, regarded that the performance of Shaoxing Xiaobaihua Yue Opera Troupe is wonderful and touching, which fully embodies the charm of Chinese excellent culture and Yue opera, and plays a good role in promoting cultural exchanges between China and Thailand.

On March 21, 2002, Shaoxing Xiaobaihua Yue Opera Troupe performed in Singapore, with repertoires such as Breaking Open the Mountain to Rescue Mother and Substituting a Raccoon for the Crown Prince. The performance lasted for more than ten days and was warmly welcomed by the Singaporean audience.

Besides, Zhejiang Yue Opera Troupe is also trying to expand its overseas influence by expanding foreign exchanges. During its performance in Finland, the classical work Liang Shanbo and Zhu Yingtai made the Europeans infatuated and caused the wife of the President of Finland to burst into tears. When Zhejiang Xiaobaihua Yue Opera Troupe went to the United States for commercial performances, there was ceaseless applause at the end of the performance, which showed that the American audiences not only understood the drama but also were deeply moved by the plot and the superb performance of the actors (Cai \& Chen, 2011).

In addition, publishing and Internet media have also been mobilized. For example, in 2008, Renmin University of China, in conjunction with Foreign Language Teaching and Research Press, launched the "Overseas Communication Project of Chinese Opera", which used English to tell opera stories and promote opera culture overseas. Yue Opera Liang Shanbo and Zhu Yingtai was also included. Besides, many large Yue Opera troupes have their own publicity websites and official accounts, which to a certain extent allows audiences at home and abroad to have more channels to understand Yue Opera.

\section{Existing Problems of Overseas Communication of Yue Opera}

As mentioned in Chapter 2, Harold Lasswell, a pioneer of American communication studies, put forward five elements of communication: who (communicator), says what (content), in which channel (media), to whom (audience), and with what effect (effect). This theoretical system has a positive guiding significance for the realization of effective communication. In recent decades, the government and non-governmental organizations have spared no effort to actively promote the crosscultural communication of Yue Opera, the good news is that some achievements have indeed been made. With the continuous enrichment of cross-cultural communication activities of Yue Opera, it has been known to more and more overseas audiences. However, at the same time, some problems are exposed. In this chapter, the author analyzes the problems existing in the cross-cultural communication of Yue Opera from five aspects based on Lasswell's Model of Communication, so as to provide a practical basis for the proposal of cross-cultural communication strategies in the following chapter.

4.1 Communicator: Seriously Insufficient in Number

The external dissemination of Yue Opera is dominated by the relevant institutions and organizations of the Chinese government, and at the same time, individuals, organizations, and enterprises related to Yue Opera also actively participate in overseas communication. At present, the main forms of cross-cultural communication of Yue Opera are overseas performances organized by the government or non-governmental organizations, as well as the overseas distribution of opera films. In this process, in addition to giving full play to the organizational role of the government and non-governmental organizations, the strength of individuals should not be underestimated.

In the overseas communication of Yue Opera, there are mainly two types of individuals that function as the main communicators. One is the actresses of Yue Opera, and the other is the translators and scholars of Yue Opera. On the one hand, the professional requirements of Yue Opera actresses are particularly high, so it takes a long period to cultivate an excellent actress. However, compared with movie and TV stars, the income of these actresses is relatively low. In other words, the input-output ratio of becoming a Yue Opera actress is not high. This has led to a large brain drain of Yue Opera. Fewer and fewer young people are willing to choose to become Yue Opera actresses, which has led to the extreme shortage of excellent actresses of Yue Opera. On the other hand, the current overseas communication activities of Yue Opera lack strong support from cross-cultural communication scholars and translators, and there is a considerable shortage of opera translators. There are many scholars studying subtitle translation and literary translation, but few of them are engaged in the introduction and translation of Yue Opera. This has something to do with the professionalism of Yue Opera translation. Yue Opera artists have a good understanding of Yue Opera culture, but they don't know foreign languages and cultures; translators and cross-cultural experts know foreign languages and cultures very well, but they lack the professional knowledge of opera. As a result, they also face a lot of difficulties in the introduction and translation of Yue Opera.

4.2 Content: Lack of Creativity and Low Level of the Internationalization

First of all, in the process of overseas communication, the performance content of Yue Opera lacks the characteristics of the times. Opera can be divided into three types: traditional opera, newly-written historical opera, and modern opera. In the overseas promotion of Yue Opera, traditional operas that best represent Chinese culture are most likely to be chosen since foreigners are believed to be more interested in Chinese traditional culture. In this way, the dissemination of traditional opera can achieve the purpose of publicizing Chinese traditional culture and values as well as showing China's cultural soft power. Therefore, in the past external communication of Yue Opera, most of the repertoires selected for overseas performances were traditional ones, such as Liang Shanbo and Zhu Yingtai, A Dream of Red Mansions, The Romance of Western Chamber and so on. If things go on like this, overseas audiences are likely to form a stereotype of Yue Opera, believing that Yue Opera is an outdated and lacking innovative play, which is obviously not conducive to the overseas promotion of Yue Opera. 
Secondly, Shaoxing dialect is often used in the performance of Yue Opera, and overseas audiences need to rely on subtitles to help better understand the plot. However, the subtitle translation of Yue Opera is relatively scarce. The translation of relevant materials of Yue Opera is mostly done by non-professional translation companies. This will seriously affect the presentation quality of Yue Opera when it is performed abroad.

Thirdly, the publicity websites and other audio-visual materials of Yue Opera are less internationalized. Complete and qualified translation materials are quite limited, to make matters worse, there are many translation errors and cultural deficiencies in the existing materials. All these have created a lot of obstacles for overseas fans to deeply understand Yue Opera.

\subsection{Medium: Lack of Diversity and Weak Interaction}

Communication channel refers to the medium and path through which both parties communicate and exchange information during the communication process. Art communication is the process by which the communicators transfer the works of art and related information to the recipients through specific media and communication paths. To realize the external communication of Yue Opera, it is inseparable from the media that can transmit artistic information by running across different times, places, histories, and cultures, and it is also inseparable from the effective art communication path (Zhang, 2017). However, at present, the cross-cultural communication of Yue Opera is mainly through face-to-face stage performance, which is insufficient and single.

At the same time, there are still some problems in the construction of Yue Opera-related websites, such as insufficient updating and weak interaction. Besides, the advantages of new media communication have not been effectively brought into play. All of these have greatly affected the cross-cultural communication of Yue Opera.

4.4 Audience: Lack of Enough Understanding of Yue Opera

The overseas audience of Yue Opera is basically the overseas Chinese and a few foreign citizens who are interested in Chinese culture. Compared with Beijing Opera, Yue Opera is less well-known overseas and its audience is relatively limited. According to the feedback of the Sydney Yue Opera Troupe, among the 400 audiences of a special performance of Yue Opera, most of them are Chinese, and westerners account for only 10\%. It can be seen that Yue Opera has not entered the vision of the western mainstream society, and many people still know little about it. This is obviously not conducive to the development of Yue Opera overseas, nor can it truly achieve the high-quality output of Chinese traditional culture.

Secondly, many audiences of Yue Opera have a certain kind of stereotype, regarding that Yue Opera is too traditional and far from the popular culture of the times. In other words, Yue Opera is considered as an outdated art form. This stereotype has seriously affected the overseas promotion of Yue Opera. In the long run, it may even cause a vicious circle, resulting in fewer and fewer Yue Opera fans overseas.

4.5 Effect: Low than Expected

Due to language barriers, cultural differences, and other reasons, overseas audiences have difficulty in understanding Yue Opera, and therefore, the communication effect is not so satisfying. In the process of enjoying the opera, even if there are subtitles, due to cultural differences, overseas audiences have difficulties in understanding the plot and some allusions, and thus unable to produce emotional resonance with the performers.

Besides, when it comes to traditional Chinese operas, the first reaction of westerners is Beijing Opera. Although Yue Opera is the second-largest type of opera in China, due to its locality, westerners still lack the necessary understanding of Yue Opera, which also leads to many obstacles in the overseas promotion of Yue Opera.

\section{Cross-cultural Communication Strategies of Yue Opera}

Cross-cultural communication of Chinese traditional opera and the continuous expansion of its overseas influence are not only an important issue that traditional opera art needs to face in contemporary development but also one of the indispensable means for China to enhance cultural soft power and realize the strategy of developing a strong culture. Given the problems discussed above, in this chapter, the author will put forward effective strategies to promote the cross-cultural communication of Yue Opera according to Lasswell's Model of Communication.

\subsection{Encouraging the Diversification of Communicators of Yue Opera}

To promote Yue Opera to all parts of the world, it is not enough to rely solely on Yue Opera artists. The government and professional troupes should actively play an organizational and coordinating role. At the same time, more overseas Chinese, foreign students, overseas opera groups, and Confucius Institutes should be encouraged to join in the overseas promotion of Yue Opera, so as to further expand its influence abroad.

First of all, the government and professional troupes should actively participate in the overseas promotion of Yue Opera, and provide as much human, material, and financial support as possible. The government should attach importance to the export of excellent Chinese culture while doing a good job in foreign economic and trade cooperation.

Secondly, the power of overseas Chinese should not be ignored in the cross-cultural communication of Yue Opera. Overseas Chinese in foreign countries are also carriers and powerful communicators of Chinese culture. Almost all the Chinese opera troupes in western countries were founded by overseas Chinese, who became the first practitioners to spread Chinese opera overseas.

Thirdly, in addition to overseas Chinese, foreign students in China are also the main force of communication. With the increase of China's comprehensive national strength and the vigorous development of cultural industry, the number of 
foreign students studying in China has increased year by year in recent years. These students were influenced by Chinese traditional culture during their study in China, which also lays the foundation for them to spread Chinese culture after returning home.

Moreover, thousands of Confucius Institutes can also be a good communication platform for Yue Opera. The integration of Yue Opera training into the Confucius Institute curriculum will not only help students learn Chinese but also help students better understand Chinese traditional culture and feel the charm of Chinese culture.

\subsection{Promoting the Innovation of Communication Content}

The choice of cross-cultural communication content of Yue Opera should take into account both tradition and innovation.

First of all, when conducting overseas dissemination of Yue Opera, it is first necessary to respect tradition and classics and focus on creating a high-quality Yue Opera repertoire. As one of the first batches of intangible cultural heritages in China, Yue Opera has a profound cultural connotation, which fully reflects the excellent traditional virtues of the Chinese people. To better disseminate this local opera genre, the overseas spread of Yue Opera must take the traditional culture as the main basis and tell Chinese stories well.

Secondly, we must pay attention to the reform and innovation in the overseas dissemination of Yue Opera, enhance its cross-cultural attraction, and change people's stereotypes towards it. To achieve this, we should innovate Opera repertoire according to people's current lifestyle and aesthetic orientation. It is also feasible to adapt Yue Opera based on western classic dramas, thereby shortening the psychological distance between overseas audiences and Chinese traditional opera, and better promoting the overseas spread of Yue Opera. For example, the Yue Opera Coriolanus and Du Liniang, which hybridized British playwright Shakespeare's Coriolanus with Chinese playwright Tang Xianzu's Peony Pavilion, wins praise from foreign audiences, and is known as a model of the combination of Chinese and western dramas (Chen, 2020).

5.3 Broadening the Cross-cultural Communication Channels of Yue Opera

In the cross-cultural communication of Yue Opera, diversified media and methods should be used to propagate and build momentum, so as to realize the successful cross-cultural communication of Yue Opera culture.

In the new media era, although it is easy for the audience to obtain performance videos on the Internet, the effect of live performance is incomparable with that of online viewing. Therefore, stage performance is still the main form of communication, and it is necessary to make bold attempts and innovations, and actively use modern technology to improve the expressiveness of drama performance.

Secondly, modern methods such as new media should be fully utilized. In the era of "Internet plus" today, with the rapid development of the Internet, network communication has become the most important part of mass media. The trend of multimedia integration is increasing, and the field of communication is expanding rapidly. In this regard, the overseas communication of Yue Opera should make full use of Internet technology to meet the diverse needs of overseas audiences.

5.4 Strengthening the Research on the Needs of Overseas Audiences

From the perspective of communication object, the overseas promotion of Yue Opera should strengthen the research on the needs of foreign audiences, and at the same time, avoid misunderstandings caused by cultural differences. The smooth progress of overseas exchanges of Yue Opera largely depends on whether foreign audiences' needs for Chinese traditional culture are met. Only when we fully understand the needs of foreign audiences, can we innovate the forms of expression of Yue Opera, so as to realize the overseas dissemination of Yue Opera.

Secondly, in the process of overseas promotion of Yue Opera, we should try to avoid misunderstandings caused by cultural differences. Yue Opera contains rich Chinese elements, which is regarded as a concentrated display of traditional Chinese culture. However, due to cultural differences, these Chinese elements sometimes cannot be correctly understood by foreign audiences, and may even cause cross-cultural conflicts. This requires us to pay attention to the introduction and translation of Yue Opera in the process of its overseas dissemination.

\subsection{Improving the Cross-cultural Communication Effect of Yue Opera}

China's extensive and profound traditional culture is the most basic part of cultural soft power and the spiritual home on which the Chinese nation depends. Yue opera, with a long history, is one of the cornerstones of Chinese culture and an outstanding representative of Chinese culture. It should play a unique role in the process of spreading Chinese civilization. By encouraging the diversification of communicators, promoting the innovation of communication content, broadening the cross-cultural communication channels, and strengthening the research on the needs of overseas audiences, the writer believes that the cross-cultural communication effect of Yue Opera will be greatly enhanced.

\section{Conclusion}

Under the background of "Chinese Culture Going Global", in the process of cross-cultural communication, Yue Opera should seize the opportunity, update the concept, innovate the content and means of communication, and tell the "Chinese story" of Yue Opera in a way that the audience is easy to understand and willing to accept, so as to enhance its overseas influence and attraction. 


\section{References}

Cai, Z. E., \& Chen, X. X. (2011). Overseas dissemination of Chinese art and its cultural influence. Huashan Literature and Art Publishing House.

Chen, L. M. (2020). Overseas translation of Yue Opera from perspective of Polysystem Theory. Journal of Shaoxing University, 40(7): 43-50.

Lasswell, H. D. (1948). The structure and function of communication in society. In Bryson, L. (Ed.). The communication of ideas (pp. 117). Institute for Religious and Social Studies.

Wang, X. F. (1993). Great power diplomacy. Huaxia Publishing House.

$\mathrm{Xu}$, C. (2013). Research on cross-cultural communication of traditional Chinese Opera: from "comparative culture" to "cross-cultural communication". Modern Communication, 35(04), 77.

Zhang, A. H. (2017). On the external communication of Chinese opera from Lasswell's Model of Communication. Sichuan Drama, (07), 56-61. 